\title{
Phytochemical Analysis and Antimicrobial Activity of Methanolic, Ethanolic and Acetonic Extracts of Stem Bark and Leaf of Neem Plant (Azadirachta indica)
}

\author{
Effiong Edet Bassey ${ }^{1}$, Gwana Adamu Mohammed ${ }^{2, *}$, Halima Mohammed Bala ${ }^{3}$, \\ Umeh Sophina Ogonna ${ }^{1}$, Bagudu Buhari Yawuri ${ }^{4}$, Okoli C. Maduchi ${ }^{1}$ \\ ${ }^{1}$ Department of Applied Microbiology and Brewing, Nnamdi Azikiwe University, Awka, Nigeria \\ ${ }^{2}$ Laboratory Unit, A. H. P Department, Mohamet Lawan College of Agriculture, Maiduguri, Nigeria \\ ${ }^{3}$ Depatment of Basic Science and Technology, Mohamet Lawan College of Agriculture, Maiduguri, Nigeria \\ ${ }^{4}$ Department of Science Laboratory Technology, Waziri Umaru Federal Polytechnic, Birnin Kebbi, Nigeria
}

\section{Email address:}

edetbassey69@gmail.com (Effiong Edet Bassey),admuwana@yahoo.com (Gwana Adamu Mohammed), halima.mohmmedbala@yahoo.com (Halima Mohammed Bala), so.umeh@unizik.edu.ng (Umeh Sophia Ogonna), hutawas@yahoo.com.uk (Bagudu Buhari Yawuri)

*Corresponding author

\section{To cite this article:}

Effiong Edet Bassey, Gwana Adamu Mohammed, Halima Mohammed Bala, Umeh Sophina Ogonna, Bagudu Buhari Yawuri, Okoli C. Maduchi. Phytochemical Analysis and Antimicrobial Activity of Methanolic, Ethanolic and Acetonic Extracts of Stem Bark and Leaf of Neem Plant (Azadirachta indica). Journal of Diseases and Medicinal Plants. Vol. 2, No. 3, 2016, pp. 14-25. doi: $10.11648 /$ j.jdmp.20160203.11

Received: December 30, 2015; Accepted: February 28, 2016; Published: June 7, 2016

\begin{abstract}
This study was carried out on phytochemicals and in vitro screening of antibacterial potentials of ethanolic, methanolic and acetonic extracts of stem bark and leaves of Neem plant (Azadirachta indica) by using the methods of AOAC; and agar diffusion technique. The extracts of the leaves and the stem bark were prepared and screened for the presence of different phytochemicals. The results obtained showed that both the leaf and stem bark extracts contain alkaloid, flavonoid, reducing sugar, tannin, saponin and polyphenol. The extracts were tested against selected pathogens; Staphylococcus aureus, Pseudomonas aeruginosa, Escherichia coli, Aspergillus niger, Aspergillus fumigatus and Candida albicans by using agar well diffusion technique. In this present research work, the acetonic, ethanolic and methanolic leaves and bark extracts of Neem plant were investigated for antimicrobial activity against these selected pathogens. The Minimum inhibitory concentration (MIC) and minimum bactericidal concentration (MBC) were determined. The MIC for the bacterial isolates was $25 \mathrm{mg} / \mathrm{ml}$ of the leaf extracts and that for stem bark was $6.25 \mathrm{mg} / \mathrm{ml}$. The MBC was $25 \mathrm{mg} / \mathrm{ml}$. Results showed that the bark extract exhibited strongest antimicrobial activity against bacteria and fungi at different concentrations when compared with the activity of the leaf extract. The acetonic stem bark extract had the highest antibacterial activity with a zone of inhibition of 22 $\mathrm{mm}$, and then followed closely by the stem bark's ethanol extract with a zone of inhibition of $21 \mathrm{~mm}$. More so, the methanolic stem bark extract had the highest antifungal activities with a zone of inhibition of $22.50 \mathrm{~mm}$. Thus, this work showed that both leaf and stem bark extracts had some phytochemicals and antimicrobial activity.
\end{abstract}

Keywords: Antimicrobial Activity, Bactericidal, Concentration, Alcoholic Extracts, Inhibitory, Minimum, Azadirachta indica, Phytochemical

\section{Introduction}

In recent years, secondary plant metabolites (photochemical), with unknown pharmacological activities have been extensively investigated as a source of medicinal agents been produced $[4,5,6]$. According to World Health Organization (WHO) medicinal plants would be the best source to obtain a variety of drugs [22]. Many parts of this plant (leaves, stem bark, and latex) have reported to exhibit 
antibacterial activity [21]. There are more than 35,000 plants species with various phytochemicals in them being used in various human cultures and veterinary around the world for medicinal purposes. About $80 \%$ of individuals from developed and underdeveloped countries use traditional medicine, which has compound derived from medicinal plants in various form of therapies $[13,11,10]$. There are more than a thousand known preventive chemicals in plants that ward off diseases; these are known as phytochemicals [24]. Phytochemical is a word derived from Greek. Phyto means plant. Any plant derived chemical is called a Phytochemical. Phytonutrient is synonym to Phytochemical. These phytonutrients differ from traditional nutrients, because they are not essential for life. They are primarily called Phytochemical for clarity $[4,25,23]$.

The plant Neem (Azadirachta indica) Meliaceae, commonly known as Neem is native of India and naturalized in most tropical and sub-tropical countries is of great medicinal value and distributed wide spread in the world. Neem is an omnipotent tree and as acrid gift of nature. The $A$. indica is a very useful traditional medicinal plant in the African sub-continent and each part of the tree has some medicinal properties $[19,1,8]$. Neem tree is a tree in the mahogany family Meliaceae, is evergreen tree found in most tropical countries. Neem has been used extensively by human kind to treat various ailments before the availability of written records which recorded the beginning of history $[14,17,23]$. Since pre-historic times, Neem has been used by human kind. Neem trees (leaf, stem, bark and seed) are known to antibacterial, antifungal activities against different pathogenic microorganisms and antiviral activity against Vaccinia, Chikungunya, measles and Coxsakie B viruses. Neem also contain biologically active principles isolated from different parts of the plant include: azadirachtin, meliacin; gedunin, salanin, nimbin, valassin, and many other derivatives of these principles. Meliacin forms the bitter principles of Neem seed oil; the seed also contain tignic acid (5-methyl-2-butanicacid) responsible for the distinctive odour of the oil [17]. These compounds belong to natural products called triterpenoids (limonoids). The active principles are slightly hydrophilic, but freely lipophilic and highly soluble in organic solvent like hydrocarbon, alcohols, ketones and esters. Also, Neem twigs are used as tooth brushes in some tropics [8].

However, the presence of the phytochemical constituents such as alkaloids, flavonoids, tannins, and phenolic compounds has been reported to be important compounds in many other medicinal plants [14]. These secondary metabolites are organic compounds that are not directly involved in the normal growth, development and reproduction of organisms. Absence of secondary metabolites does not result in immediate death, but long term impairment of organisms. They play an important role in plant defense. The secondary metabolites are used for medicine, flavourings and recreational drugs. These compounds after possible chemical manipulation provide and improved drugs to treat the infectious diseases [19].
With the increasing failure of chemotherapeutics and antibiotic resistance exhibited by pathogenic microbial agents has led to the screening of several medicinal plants for their potential antimicrobial activity. Plants produce a diverse range of bioactive molecules, making them rich sources of different types of medicines; therefore, such plants with possible antimicrobial activities need to be tested. This study is aimed at screening for phytochemical properties and investigating the antimicrobial activity of methanolic, ethanolic and acetonic extracts of stem bark and leaf of Neem against some pathogenic bacteria and fungi.

\section{Materials and Methods}

The following standard materials were required and used in the cause of this scientific research study and Standard Operation Procedures (SOP) are absolutely been observed. Materials and reagents (Biotec, H\&B Warners, Merck and Pfizer product) for this study were of analytical grade and were obtained commercially.

\subsection{Sampling and Samples Collection}

The samples of plant parts (leaves and stem bark) of Neem plant (Azadirachta indica) were collected in the month of January, 2015 from the tree growing in side environs of Nnamdi Azikiwe University, Awka. They were identified by a Botanist, Maxwell Nwata from the Department of Botany, (the plant is locally called Mbritem or native name given by Igbo language) the voucher specimen were deposited in herbarium (ASC Number 221) within the same department and University, and finally transported to the Research Laboratory, Department of Applied Microbiology and Brewing, in the same University.

\subsection{Preparation of the Samples}

The plant parts materials obtained were prepared and standard operation procedures (SOP) are absolutely being observed and as described by Gwana et al, (2014).

\subsubsection{Pulverization of the Samples}

After the collection and authentication of the samples, the leaves were destalked carefully. The leaves and the stems bark were separately washed under running tap water. Each sample was washed with distilled water and finally with deionised water in order to eliminate dust and other foreign particles. But the stems bark was chopped in to pieces with a sharp knife before washing them. They were shade dried for 12 days at room temperature. After which the barks were grinded in to powder by using a blender (homogenizer) and the leaves were grinded in to fine powder by using a mortar and pestle, and subsequently by a blender. Each sample was transferred and packed in to clean, grease free and sterilized plastic bottle. They were labeled, B-leaf and C-bark for the leaves powder and the stems bark powder respectively. The labeled plastic bottles containing the plant powders samples were airtight screwed and capped, stored at dry and cool condition, kept away from light and under temperature of 
$18^{\circ} \mathrm{C}$ to $25^{\circ} \mathrm{C}$ ready for extraction.

\subsubsection{Preparation of Crude Extracts of the Samples}

About 10 grams of the each sample (B-leaf and C-bark) were electronically weighed in to six $250 \mathrm{ml}$ conical flasks ( 3 flasks for each sample). One hundred $\mathrm{ml}$ of each solvent (absolute acetone, ethanol and methanol) were added in to each flask, and shaken with a vibrator - shaker (that can house six conical flasks) for 4 hours at room temperature. The movement of the vibrator - shaker serves to disrupt the plant tissue so that the solvents were allowed in to the tissue resulting in adequate extraction.

On completion of homogenization, the mixture was filtered using Whatman filter paper Nol at room temperature $\left(30^{\circ} \mathrm{C}\right)$. The extracts were labeled appropriately as followed; $\mathrm{B}$ acetone, $\mathrm{BA}$; $\mathrm{B}$ ethanol, $\mathrm{BE}$; $\mathrm{B}$ methanol, $\mathrm{BM}$ for the sample $\mathrm{B}$ - leaf and $\mathrm{C}$ acetone $\mathrm{CA}, \mathrm{C}$ ethanol $\mathrm{CE}$ and $\mathrm{C}$ methanol, $\mathrm{CM}$ for sample $\mathrm{C}-$ bark respectively. Then each sample was dispensed in to a sterile beaker and placed in the water bath for evaporation at the boiling point of each solvent After evaporation, the residual masses obtained individually were measured and dimethyl-sulfoxide (DMSO) was used to prepare a starting concentration of $100 \mathrm{mg} / \mathrm{ml}$ for all the extracts. All the extracts were stored in refrigerator at $4{ }^{\circ} \mathrm{C}$ until when needed. Another 10 grams of each sample were weighed individually in to six $250 \mathrm{ml}$ conical flask and 100 $\mathrm{ml}$ of each solvent were added and shaken with a vibrator shaker for 4 hours at room temperature. On the completion of homogenization, filtration, the extracts were labeled and kept in a refrigerator at $4^{\circ} \mathrm{C}$ for phytochemical screening on each of the solvent extract.

\subsection{Phytochemical Analysis}

The extracts were analyzed to test for the presence of the active chemical constituents such as alkaloid, tannin, saponins, steroid, flavonoids, anthraquinones, hydroxyl methyl anthraquinones, reducing sugar, polyphenol, terpenoid and cardiac glycoside. The phytochemical analysis was done on the two samples, leaves (B) and bark (C) using the following solvent extract - acetone, methanol, and ethanol by using the methods of AOAC, (1990); Egan et al, (1981).

\subsubsection{Mayer's Test for Alkaloids}

The following procedures were performed.

i. Procedure:-

$2 \mathrm{ml}$ of acetonic leaf extract was added in to a test tube and the mixture was heated for 20 minutes using water bath. The heated mixture was filtered and $1 \mathrm{ml}$ of the filtrate was measured in to a test tube and $0.5 \mathrm{ml}$ of Wagner's reagent was added to it. A reddish brown coloration was observed.

ii. Frothing test

Procedure:-

$3 \mathrm{ml}$ of the acetonic leaf extract was pipette in to a test tube; $2 \mathrm{ml}$ of distilled water was added to it. Then it was shaken vigorously. A persistence frothing movement was observed.

\section{iii. Emulsion test}

Procedure:-3 $\mathrm{ml}$ of the acetonic leaf extract was pipette out in to a test tube and 5 drops of olive oil was also incorporated in to it and then it was shaken vigorously emulsification was observed (tiny droplets incorporated in to the body of the extract).

\subsubsection{Lieberman - Buchard's Test for Steroids}

Procedure:-1 $\mathrm{ml}$ of the extract was treated with $0.5 \mathrm{ml}$ of acetic acid, $0.5 \mathrm{ml}$ of chloroform and $1 \mathrm{ml}$ of concentrated $\mathrm{H}_{2} \mathrm{SO}_{4}$ was also added to it. A reddish brown ring was formed at the separating level of the two liquids indicating the presence of steroids.

\subsubsection{Sodium Hydroxide's Test for Flavonoids \\ Procedure:-}

$3 \mathrm{ml}$ of the acetonic leaf extract was pipette out and $10 \mathrm{ml}$ of distilled water was added to it and it was shaken and $1 \mathrm{ml}$ of $10 \% \mathrm{NaOH}$ was also added in to the mixture. A yellow coloration was observed showing the presence of flavonoid.

\subsubsection{Ferric chloride's Test for Tannins}

Procedure:-1 $\mathrm{ml}$ of the extract was measured in to a test tube and it was heated. One drop of $10 \%$ ferric chloride was added to it. The mixture showed a green coloration.

\subsubsection{Free / Combined Anthraquinones Test}

Procedure:-2 $\mathrm{ml}$ of leaf extract was shaken with $5 \mathrm{ml}$ of $10 \%$ ammonia solution. The mixture was shaken and the presence of a pink - red to violet colour in the ammoniacal (lower) phase indicated by the presence of anthraquinones.

\subsubsection{Bourn stranger's Test for Hydroxyl Methyl Anthraquinones \\ Procedure:-}

$2 \mathrm{ml}$ of acetonic extract was treated with $5 \mathrm{ml}$ of $10 \%$ ammonia solution. The formation of a red coloration or precipitate indicates the presence of hydroxyl methyl anthraquinones.

\subsubsection{Free Reducing Sugar's Test for Reducing Sugar \\ Procedure:-}

$2 \mathrm{ml}$ of acetonic extract in a test tube was added to $5 \mathrm{ml}$ of Fehling solutions and heated in a water bath at $80^{\circ} \mathrm{C}$ for 10 minutes. The formation of a brick red precipitate or solution was taken; as an evidence for the presence of reducing compounds.

\subsubsection{Test for Polyphenol}

Procedure:-To $2 \mathrm{ml}$ of extract was added $5 \mathrm{ml}$ of distilled water and heated in a water bath for 10 minutes. $1 \mathrm{ml}$ of ferric chloride was added to the mixture followed by $1 \mathrm{ml}$ of $1 \%$ potassium ferricyanide. The formation of a green - blue coloration indicated the presence for polyphenol.

\subsubsection{Salkowski's Test for Terpenoid}

Procedure:-

$5 \mathrm{ml}$ of each extract was mixed with $2 \mathrm{ml}$ of chloroform $\left(\mathrm{CHCl}_{3}\right)$ in a test tube. $3 \mathrm{ml}$ of concentrated $\mathrm{H}_{2} \mathrm{SO}_{4}$ was carefully added to the mixture to form a layer. An interface 
with reddish brown coloration was formed, if terpenoid constituent is present.

\subsubsection{General Test for Cardiac Glycoside \\ Procedure:-}

$0.5 \mathrm{~g}$ of each extract was dissolved in $2 \mathrm{ml}$ of chloroform. Concentrated $(2 \mathrm{ml})$ sulphuric acid was carefully added to it to form a lower layer; a reddish - brown colour at the interface indicated the presence of a steroidal ring (a glycogen portion of the cardiac glycoside).

\subsection{Preparation of Culture Media}

The experiments were conducted under sterile condition and hygienic environment. The media used were Muller Hinton Agar (Biotec product), Sabouraud Dextrose Agar (Merck product), Nutrient Broth (Biotec), Sabouraud Dextrose Broth (Merck) and Nutrient agar (Biotec). The antimicrobial drugs used were Fluconazole (Pfizer) and ciprofloxacin (Pfizer product) for fungi and bacteria isolates respectively. The media were prepared according to the manufacturer's instructions. The Muller Hinton agar (MHA) was used for the bacteria, while the Sabouraud Dextrose Agar was used for the fungi. After preparing the two media, they were allowed to cool to $45^{\circ} \mathrm{C}$ before dispensing aseptically in to fourteen (14) plastic Petri dishes each. The plates were allowed to solidify before inversion.

\subsubsection{Source of Microorganisms}

The organisms used were Escherichia coli, Pseudomonas aeruginosa, Staphylococcus aureus, Aspergillus niger, Aspergillus fumigatus and Candida albicans. The organisms were obtained from Glanson Medical centre, Awka and Department of Applied Microbiology and Brewing Laboratory stock culture, Azikiwe University, Awka, Nigeria.

\subsubsection{Maintenance of Organisms (Bacterial and Fungal) Isolates}

The organisms were maintained in agar slant wrapped with aluminium foil and kept in the refrigerator at $4^{\circ} \mathrm{C}$.

\subsubsection{Fungal Isolate}

They were maintained in agar slants containing Sabouraud Dextrose agar. They were carefully wrapped aluminium foil and kept in the refrigerator at $4^{\circ} \mathrm{C}$.

\subsubsection{Inoculums Preparation}

The Bacterial and fungal inoculums were prepared by inoculating a loopful of test organisms in $10 \mathrm{ml}$ of nutrient broth in to three separate Bijou bottles (for bacterial isolates) and $10 \mathrm{ml}$ of Sabouraud dextrose broth (SDB) in to three separate Bijou bottles (for fungal isolates). They were incubated at $37^{\circ} \mathrm{C}$ and $25^{\circ} \mathrm{C}$ for $4-6$ hours for bacteria and fungi respectively till a moderate turbidity were developed.

\subsubsection{Standard Antibiotic}

The standard drug of quality; Ciprofloxacin and Fluconazole (Pfizer product) were obtained commercially as a standard for the working concentration and antimicrobial activity test.

\subsection{Determination of Antimicrobial Activity}

The antimicrobial activity of the leaf and bark extracts (acetonic, ethanolic and methanolic) were determined using agar well diffusion method by the following procedure as described by Joanne et al., (2011). A 2 - fold serial dilution of these extracts using Dimethyl sulfoxide (DMSO) as the diluents were prepared separately to obtain $100 \mathrm{mg} / \mathrm{ml}, 50$ $\mathrm{mg} / \mathrm{ml}, 25 \mathrm{mg} / \mathrm{ml}, 2.50 \mathrm{mg} / \mathrm{ml}$ and $6.25 \mathrm{mg} / \mathrm{ml}$. Muller Hinton agar plates prepared earlier were inoculated with test organisms with the aid of sterile syringes and the bacterial inoculums $(0.1 \mathrm{ml})$ were spread on the surfaces of each media using sterile swab sticks. The plates were allowed to dry before the holes were made. Agar surfaces were cut with the help of a sterile cork borer having a diameter of $5 \mathrm{~mm}$ size to make appropriate wells.

Each leaf extract (acetonic, ethanolic and methanolic) had four plates and two holes each for the first two plates were made. Also 3 holes each in the other two plates were made (this represent $100 \mathrm{mg} / \mathrm{ml}$ and $50 \mathrm{mg} / \mathrm{ml}$ for the first two plates while the other two plates represent $2.5 \mathrm{mg} / \mathrm{ml}, 12.50$ $\mathrm{mg} / \mathrm{ml}$ and $6.25 \mathrm{mg} / \mathrm{ml}$ ).

Different concentrations - $100 \mathrm{mg} / \mathrm{ml}, 500 \mathrm{mg} / \mathrm{ml}, 25$ $\mathrm{mg} / \mathrm{ml}, 12.50 \mathrm{mg} / \mathrm{ml}$ and $6.25 \mathrm{mg} / \mathrm{ml}$ respectively of the leaf extracts were added to the holes of Escherichia coli, Pseudomonas aeruginosa and Staphylococcus aureus plates respectively.

Also, a working concentration of the ciprofloxacin (as a standard) was obtained after reconstitution and it was poured in to the wells of E. coli, Pseudomonas aeruginosa and Staphylococcus aureus plate respectively. This was done after boring two holes on each different plate for the organisms.

Sabouraud Dextrose Agar (SDA) plates were used for the fungal isolates. The SDA was dispensed in to fourteen (14) plastic Petri dishes for each extracts (acetonic, ethanolic and methanolic) and this is a total of forty - two (42) plates. 2 fold serial dilutions were also prepared using DMSO as the diluents.

However, the concentration obtained were $100 \mathrm{mg} / \mathrm{ml}, 50$ $\mathrm{mg} / \mathrm{ml}, 25 \mathrm{mg} / \mathrm{ml}, 12.50 \mathrm{mg} / \mathrm{ml}, 6.25 \mathrm{mg} / \mathrm{ml}, 3.13 \mathrm{mg} /$ $\mathrm{ml}$ and $1.56 \mathrm{mg} / \mathrm{ml}$. The SDA plates were inoculated with the organisms with the aid of sterile syringe and the fungi inoculums ( $0.1 \mathrm{ml}$ in each plate) were spread on the surfaces of each media using sterile swab sticks. The plates were allowed to dry before the holes were bored. Agar surface were cut with the help of a sterile cork borer having a diameter of $5 \mathrm{~mm}$ size to make appropriate wells. Each leaf extracts (i.e. acetonic, ethanolic and methanolic) had four plates and four (4) holes on each plate were made. The SDA plates for the standard drug (Fluconazole) were six - two for each organism. Two holes were bored on the six (6) plates (a total of 14 plates for each organism were used).

Different concentrations of the serially diluted plant extracts were added in to the holes of Aspergillus niger, Aspergillus fumigatus and Candida albicans plates respectively. Also, the working concentration of the reconstituted Fluconazole was added in to the wells of 
Aspergillus niger, Aspergillus fumigatus and Candida albicans plates respectively.

In addition, the same procedures were used for the bark extracts (acetonic, methanolic and ethanolic) for fungi and bacteria culture. The plates were left for some time to allow for the diffusion of extracts and drugs before incubation. Bacterial cultures were incubated at $37^{\circ} \mathrm{C}$ for 24 hours and fungal cultures at $25^{\circ} \mathrm{C}$ for 48 hours. Antimicrobial activities were determined by measuring the zone of inhibition surrounding the well in millimeter $(\mathrm{mm})$ using a pair of divider and a ruler. Each concentration included duplicates and also the drugs (standard). The results are average of the two independent experiments. The results were recorded on tables.

\subsection{Cultural Characteristics}

The bacterial isolates were cultured on different selective media. For E. coli on EMB agar was used, Staphylococcus aureus on Mannitol Salt agar and Pseudomonas on Centrimide agar were used for Pseudomonas aeruginosa and the following tests were used to confirm the bacterial isolates; Gram staining reaction, Biochemical tests: Catalase, Coagulate, Indole, Methyl red, Voges proskaeur, Urease tests, and Motility, while fungi isolates were confirmed by germ tube and slide culture tests.

\subsection{Determination of Minimum Inhibitory Concentration MIC}

The minimum inhibitory concentration values were determined by broth dilution assay. 2 - fold serial dilutions for MIC of each extracts (leaf and bark acetonic, ethanolic and methanolic extracts) were prepared. To perform MIC experiment, four (4) test tubes were taken, washed and dried. $0.5 \mathrm{ml}$ of nutrient broth was dispensed to each test tube, plugged the mouths and sterilized at $121^{\circ} \mathrm{C}$ for 15 minutes. After cooling, $0.5 \mathrm{ml}$ plant extract from the stock $(100 \mathrm{mg} /$ $\mathrm{ml}$ ) test tube was added to the first test tube was mixed properly and $0.5 \mathrm{ml}$ mixture of this test tube was transferred to the next (second) test tube. $0.5 \mathrm{ml}$ was taken from this second test tube and dispensed it to the third test tube, and then the procedure was repeated until the fourth $\left(4^{\text {th }}\right)$ test tube. $0.5 \mathrm{ml}$ from the last test tube was removed and discarded. Then $0.5 \mathrm{ml}$ bacterial culture ( $4-6$ hours old) were added to each test tube and incubated at $37^{\circ} \mathrm{C}$ for $18-24$ hours. Controls were done simultaneously. The first control test tube contains $0.5 \mathrm{ml}$ of nutrient broth and $0.5 \mathrm{ml}$ of the test organism, while the other control test tube contains $0.5 \mathrm{ml}$ of nutrient broth and $0.5 \mathrm{ml}$ of the extract. They were also incubated under the same condition.

However, for the fungal isolates, six (6) test tubes and two control test tubes. The six test tubes and the control contained Sabouraud Dextrose Broth (SDB). After washing of test tubes, drying and sterilization (at $121^{\circ} \mathrm{C}$ for 15 minutes), a 2 - fold serial dilutions were also prepared. From the stock (crude extract also $100 \mathrm{mg} / \mathrm{ml}$ ), $0.5 \mathrm{ml}$ plant extract was added to the first test tube, was mixed properly and $0.5 \mathrm{ml}$ mixture of this test tube was taken and added to the next (second) test tube. $0.5 \mathrm{ml}$ from this second test tube was taken and dispensed in to the next tube; same thing was done to the last tube subsequently. $0.5 \mathrm{ml}$ from the last test tube was discarded. Then $0.5 \mathrm{ml}$ fungal culture $(4-6$ hours old $)$ were added to each test tube and incubated for $25^{\circ} \mathrm{C}$ for 48 hours. The controls were done simultaneously. The first control contain: SDB $(0.5 \mathrm{ml})$ and test organism $(0.5 \mathrm{ml})$ while the other control had SDB $(0.5 \mathrm{ml})$ and plant extract $(0.5 \mathrm{ml})$. This procedure was done for all six (6) organisms (3 bacteria and 3 fungi) using the acetonic, ethanolic and methanolic extracts of leaves and bark respectively.

\section{Results}

Plants produce a diverse range of bioactive molecules, making them rich sources of different types of medicines and foods. Plant that produces such product, antimicrobial activities should be tested against appropriate microbes to confirm the activity and to ascertain the parameters associate with it, and this leads to the results obtained from this research work on phytochemicals and in vitro screening of antibacterial potentials of acetonic, ethanolic, and methanolic extracts of stem bark and leaves of Neem plant (Azadirachta indica), procedures of analysis were done on six organisms ( 3 bacteria and 3 fungi) were that:

Table 1 showed the serial dilution, the concentrations obtained after the 2 - fold serial dilutions before incubation were for quality control, the Neem extracts (acetonic, ethanolic and methanolic leaf and bark extracts) were separately cultured on Muller Hinton Agar (MHA) and Sabouraud Dextrose Agar (SDA) to determine their purity. After overnight incubation, no growth of any colonies of bacteria was observed. Also for the SDA after 48 hours of incubation, no growth of fungi was observed.

Table 2 and 3 showed the results of the phytochemical test which was done to find the presence of active chemical constituents such as terpenoid, polyphenol, cardiac glycoside, anthraquinones, flavonoids, saponins; steroids, tannins, alkaloids, reducing sugar and hydroxyl methyl anthraquinones.

Table 4 showed the characteristic and identification features of the fungal isolate being observed and examined.

Table 5 showed the physical characteristics of the bacterial isolates being examined.

Table 6 showed the biochemical test characteristics of the bacterial isolates being examined.

Table 7 showed the results of the antibacterial activity and antifungal activity of ciprofloxacin and Fluconazole against selected pathogens in order to ascertain the potency and efficacy of pathogens and the standard antimicrobial drugs.

Table 8 to 10 showed the results obtained from the study of the antibacterial and antifungal activities of acetone, ethanol and methanol extracts of Azadirachta indica leaf and bark which were investigated using agar well diffusion method against the selected pathogens; Pseudomonas aeruginosa, Staphylococcus aureus, Escherichia coli, Aspergillus niger, Aspergillus fumigatus and Candida 
albicans. All the examined extracts showed varying degrees of antimicrobial activities against the pathogens.

Table 11, 12 and 13 showed the results that were obtained from the analysis and it revealed the minimum inhibitory concentration (MIC) values of the acetonic (leaf; $12.5-25$ and bark; $3.13-12.5$ ), ethanolic (leaf; $6.25-25$ and bark; 6.25) and methanolic (leaf; $6.25-25$ and bark; $6.25-25$ ) of Neem Plant Parts Extracts in $\mathrm{mg} / \mathrm{ml}$ respectively.

Table 14 showed the results obtained from this study that, the minimum bacterial concentration (MBC) values of acetone $(0-25 \mathrm{~mm})$, ethanol $(12.5-25 \mathrm{~mm})$ and methanol $(0-25 \mathrm{~mm})$ extracts of Neem leaf.

Table 15 showed the results that were obtained from the analysis and it revealed the minimum bacterial concentration (MBC) values of acetone $(12.5-25 \mathrm{~mm})$, ethanol $(0-25$ $\mathrm{mm})$ and methanol $(12.5-25 \mathrm{~mm})$ extracts of Neem stem bark.

Figure 1, 2, 3, and 4 showed the antibacterial activity of acetonic, ethanolic and methanolic extract of Neem plant parts.

Table 1. Concentrations of Fungi and Bacteria obtained after the 2 -fold serial dilutions.

\begin{tabular}{lll}
\hline Type of Microbe. & Tube. & Dilution in $\mathbf{~ m} / \mathbf{m l}$. \\
\hline Fungi & $1^{\text {st }}$ & 25 \\
& $2^{\text {nd }}$ & 12.50 \\
& $3^{\text {rd }}$ & 6.25 \\
& $4^{\text {th }}$ & 3.13 \\
& $5^{\text {th }}$ & 1.56 \\
Bacteria & $6^{\text {th }}$ & 0.78 \\
& $1^{\text {st }}$ & 25 \\
& $2^{\text {nd }}$ & 12.50 \\
& $3^{\text {rd }}$ & 6.25 \\
& $4^{\text {th }}$ & 3.13 \\
\hline
\end{tabular}

$N B$ : The concentrations obtained after the 2 - fold serial dilutions before incubation.

Table 2. Qualitative Phytochemical Analysis of Acetone, Ethanol, Methanol Leaf Extract.

\begin{tabular}{|c|c|c|c|c|}
\hline \multirow{2}{*}{ Type of Phytochemical. } & \multirow{2}{*}{ Test Type. } & \multicolumn{3}{|c|}{ Type of Leaf Extract. } \\
\hline & & Acetone. & Ethanol. & Methanol \\
\hline Alkaloids & Mayer's & - & + & - \\
\hline Fronthing & & - & - & + \\
\hline Emulsification & & ++ & - & ++ \\
\hline Tannin & cchloride's & + & - & + \\
\hline Glycoside cardiac & General & - & + & - \\
\hline Cyanogenic & & - & + & - \\
\hline Flavonoid & Sodium hydroxide's & - & + & - \\
\hline Anthraquinones & Free / Combined & - & + & - \\
\hline Reducin gsugar & Free Reducing Sugar's & + & + & +++ \\
\hline Polyphenol & & - & +++ & - \\
\hline Terpenoid & Salkowski's & - & + & - \\
\hline Steroid & Sodium hydroxide's & - & + & - \\
\hline Saponins & & - & - & - \\
\hline
\end{tabular}

KEYS: $-=$ Absent,$+=$ Scanty,$++=$ Moderate,$+++=$ Abundance .

Table 3. Qualitative Phytochemical Analysis of Acetone, Ethanol, Methanol Stem Bark Extract.

\begin{tabular}{lllll}
\hline \multirow{2}{*}{ Type of Phytochemical. } & Test Type. & Type of Leaf Extract. & Ethanol. & Methanol \\
\cline { 3 - 5 } & Mayer's & - & + & + \\
\hline Alkaloids & & - & - & - \\
Fronthing & & - & + & + \\
Emulsification & Ferric chloride's & +++ & - & - \\
Tannin & General & - & - & - \\
Glycoside cardiac & & - & - & - \\
Cyanogenic & Sodium hydroxide's & + & - & - \\
Flavonoid & Free / Combined & - & - & - \\
Anthraquinones & Free Reducing Sugar's & +++ & ++ & + \\
Reducing sugar & & ++ & - & + \\
Polyphenol & Salkowski's & - & - & - \\
Terpenoid & Sodium hydroxide's & & - & - \\
Steroid & & - & - & - \\
- & & & & + \\
Saponins & & & & \\
\hline
\end{tabular}

KEYS: $-=$ Absent,$+=$ Scanty present,$++=$ Moderate,$+++=$ Abundance. 
Table 4. Fungal Isolates (Moulds) Identification

\begin{tabular}{|c|c|c|}
\hline Type of Fungus. & Cultural Characteristics. & Microscopic Characteristics. \\
\hline Aspergillus niger. & $\begin{array}{l}\text { Flat compact colonies, white at first then becoming black } \\
\text { homogeneously with grey underside. }\end{array}$ & $\begin{array}{l}\text { Septate and hyphae with erect, simple and thick walled } \\
\text { conidiophores bearing conidial heads split in to over four (4) } \\
\text { loose conidia columns with four (4) fragments apically. }\end{array}$ \\
\hline Aspergillus fumigatus. & $\begin{array}{l}\text { Flat compact colonies, white at first, then becoming then dark } \\
\text { green underside. }\end{array}$ & $\begin{array}{l}\text { Septate and hyphae with thin walled conidiophores becoming } \\
\text { heads composed of catenucleac conidial. }\end{array}$ \\
\hline Candida albicans. & $\begin{array}{l}\text { Cream coloured pasty colonies usually appear after some } \\
\text { hours }(24-48 \text { hours }) \text { incubation at } 37^{\circ} \mathrm{C} \text {, with distinctive } \\
\text { yeast smell. }\end{array}$ & $\begin{array}{l}\text { Budding cells can be easily seen and can be identify by the } \\
\text { formation of pseudohyphae and chlamydospores. }\end{array}$ \\
\hline
\end{tabular}

Table 5. Physical Characteristics of the Bacterial Isolates.

\begin{tabular}{llll}
\hline \multirow{2}{*}{ Type of Isolates. } & \multicolumn{4}{l}{ Characteristic identification of Isolates under Tests. } \\
\cline { 2 - 4 } & Cultural Appearance & Morphological Appearance. & Gram Stain Reaction. \\
\hline Escherichia coli & Green metallic sheen on EMB agar & Rod & + \\
Staphylococcus aureus & Yellow colonies on MSA & Coccus & - \\
Pseudomonas aeruginosa & Green colonies on PCA & Rod & + \\
\hline
\end{tabular}

KEYS: - = Negative, $+=$ Positive, EMB = Eosin Methylene Blue Agar, MSA = Mannitol Salt Agar, PCA = Pseudomonas Centrimide Agar.

Table 6. Biochemical Test Characteristics of the Bacterial Isolates.

\begin{tabular}{|c|c|c|c|c|c|}
\hline \multirow{2}{*}{ Type of Isolates. } & \multicolumn{5}{|c|}{ Biochemical Test of Isolates under Tests. } \\
\hline & Catalase. & Coagulase. & Indole. & Methyl Red. & Voges Proskaeur. \\
\hline Escherichia coli & - & + & + & + & - \\
\hline Staphylococcus aureus & + & + & + & + & + \\
\hline Pseudomonas aeruginosa & + & - & - & - & - \\
\hline
\end{tabular}

KEYS: - = Negative, $+=$ Positive.

Table 7. Antimicrobial Activity of Acetonic Extract of Neem Leaf and Standard Drugs Zones of Inhibition (mm).

\begin{tabular}{|c|c|c|c|c|c|c|c|}
\hline \multicolumn{2}{|l|}{$\begin{array}{l}\text { Type of } \\
\text { Concentration } \\
\end{array}$} & \multicolumn{6}{|c|}{ Zones of Inhibition by each Microbe (mm). } \\
\hline Extract. & $\mathrm{mg} / \mathrm{ml}$. & Staphyloccus aureus. & Pseudomonas aeruginosa. & Escherichia coli. & Aspergillus niger. & $\begin{array}{l}\text { Aspergillus } \\
\text { fumigatus. }\end{array}$ & $\begin{array}{l}\text { Candida } \\
\text { albicans }\end{array}$ \\
\hline \multirow[t]{7}{*}{ Leaf } & 100 & No & 12 & 10 & 8 & 12 & 10 \\
\hline & 50 & 13.50 & 9.50 & 9.50 & 10.50 & 10.00 & 8.00 \\
\hline & 25 & 9.75 & 9.00 & 7.00 & 9.00 & No & 9.00 \\
\hline & 12.50 & No & 10.00 & 6.50 & 8.50 & 14.50 & 8.50 \\
\hline & 6.25 & No & 9.00 & No & 8.50 & 13.00 & 15.50 \\
\hline & 3.13 & - & - & - & 7.00 & 16.50 & 11.50 \\
\hline & 1.56 & - & - & - & 10.00 & 15.50 & 14.00 \\
\hline Ciprofloxacin & 100 & 120 & 14.50 & 21. & - & - & - \\
\hline Fluconazole & 100 & - & - & - & 12.00 & 15.5 & 13.40 \\
\hline
\end{tabular}

Keys: No = no activity i.e. no zone of inhibition, - = this means not tested.

Table 8. Antimicrobial Activity of Acetonic Extract of Neem Stem Bark and Standard Drugs Zones of Inhibition (mm).

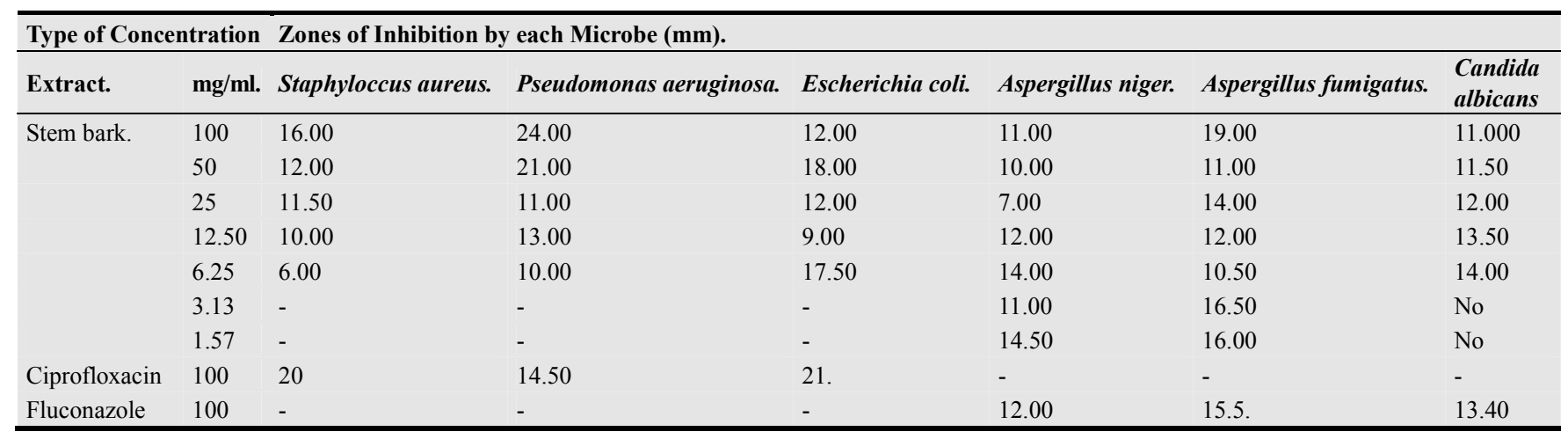

Keys: No $=$ no activity i.e. no zone of inhibition, $-=$ this means not tested. 
Table 9. Antimicrobial Activity of Methanolic Extract of Neem Leaf and Standard Drugs Zones of Inhibition (mm).

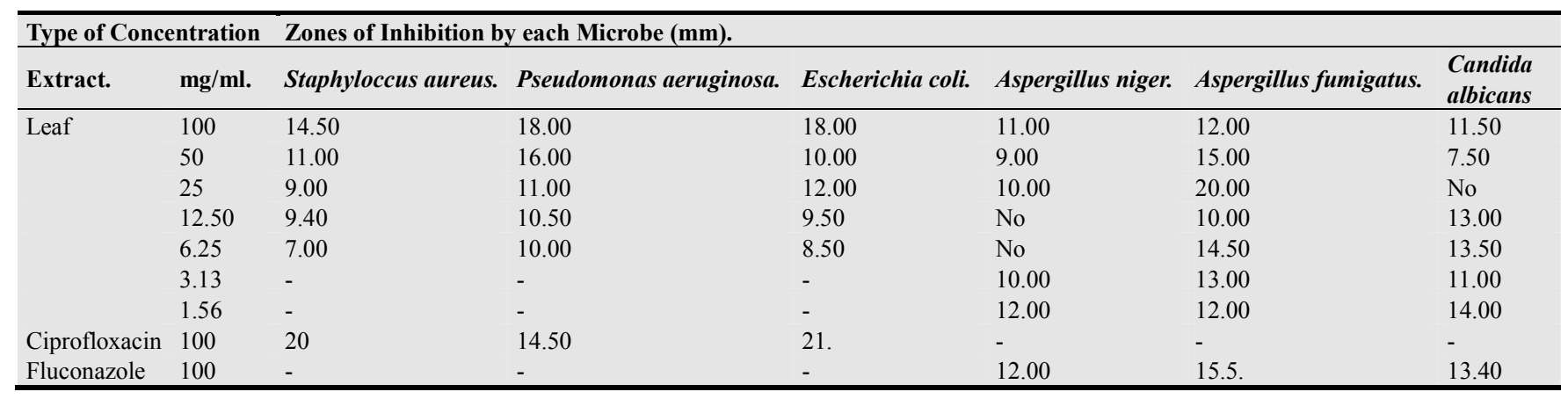

Keys: No = no activity i.e. no zone of inhibition, $-\mathbf{-}$ this means not tested.

Table 10. Antimicrobial Activity of Methanolic Extract of Neem Stem Bark and Standard Drugs Zones of Inhibition (mm).

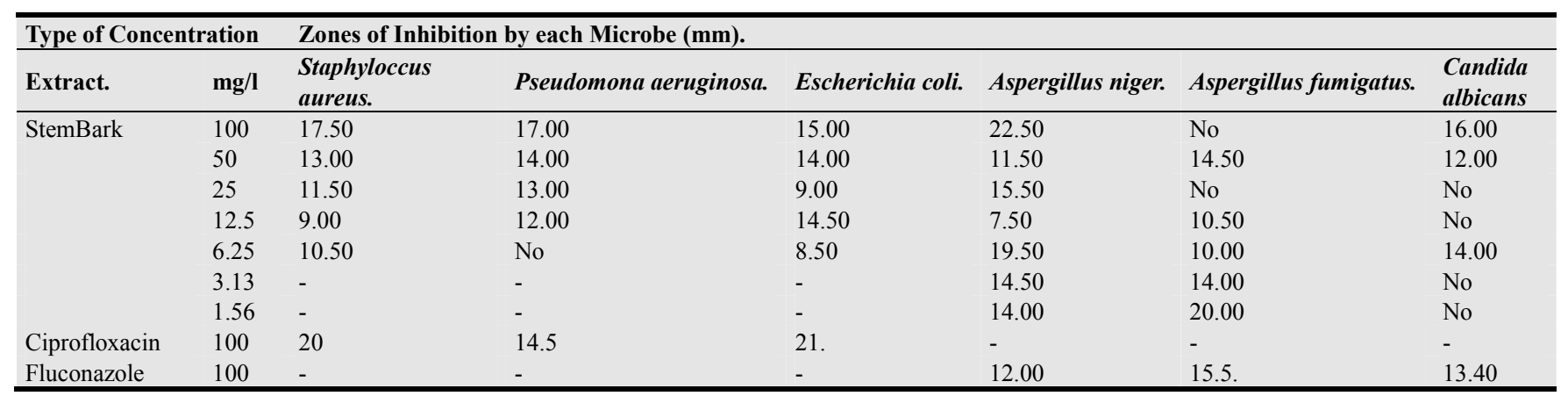

Keys: No = no activity i.e. no zone of inhibition, - = this means not tested.

Table 11. Minimum Inhibitory Concentration Values of the Acetonic Neem Plant Parts Extracts in $\mathrm{mg} / \mathrm{ml}$.

\begin{tabular}{lll}
\hline \multirow{2}{*}{ Name of Microbe. } & \multicolumn{2}{l}{ Neem Plant Parts mg / ml. } \\
\cline { 2 - 3 } & Leaf Extract. & Stem Bark Extract. \\
\hline Staphylococcus aureus & 25 & No \\
Pseudomonas aeruginosa & 25 & 6.25 \\
Escherichia coli & 25 & 6.25 \\
Aspergillus niger & 25 & 12.50 \\
Aspergillus fumigatus & 25 & 12.50 \\
Candida albicans & 12.50 & 3.13 \\
\hline
\end{tabular}

Key: $\mathrm{No}=$ value for MIC was obtained.

Table 12. Minimum Inhibitory Concentration Values of the Ethanolic Neem Plant Parts Extracts in $\mathrm{mg} / \mathrm{ml}$.

\begin{tabular}{lll}
\hline \multirow{2}{*}{ Name of Microbe. } & \multicolumn{2}{c}{ Neem Plant Parts mg / ml. } \\
\cline { 2 - 3 } & Leaf Extract. & Stem Bark Extract. \\
\hline Staphylococcus aureus & No & 6.25 \\
Pseudomonas aeruginosa & 25 & 6.25 \\
Escherichia coli & No & No \\
Aspergillus niger & 12.50 & 6.25 \\
Aspergillus fumigatus & 12.50 & 6.25 \\
Candida albicans & 6.25 & 6.25 \\
\hline
\end{tabular}

Key: No = value for MIC was obtained

Table 13. Minimum Inhibitory Concentration Values of the Methanolic Neem Plant Parts Extracts in $\mathrm{mg} / \mathrm{ml}$.

\begin{tabular}{lll}
\hline \multirow{2}{*}{ Name of Microbe. } & \multicolumn{2}{l}{ Neem Plant Parts mg / ml. } \\
\cline { 2 - 3 } & Leaf Extract. & Stem Bark Extract. \\
\hline Staphylococcus aureus & 25 & 6.25 \\
Pseudomonas aeruginosa & 6.25 & 12.50 \\
Escherichia coli & No & 6.25 \\
\hline
\end{tabular}

\begin{tabular}{lll}
\hline \multirow{2}{*}{ Name of Microbe. } & \multicolumn{2}{l}{ Neem Plant Parts mg / ml. } \\
\cline { 2 - 3 } & Leaf Extract. & Stem Bark Extract. \\
\hline Aspergillus niger & 25 & 25 \\
Aspergillus fumigatus & 12.50 & 6.25 \\
Candida albicans & 6.25 & 6.25 \\
\hline
\end{tabular}

Key: No = value for MIC was obtained

Table 14. MBC values of Acetone, Ethanol and Methanol Extracts of Neem Leaf.

\begin{tabular}{llll}
\hline \multirow{2}{*}{ Type of Microbe. } & \multicolumn{3}{l}{ Neem Leaf Extract. } \\
\cline { 2 - 4 } & Acetone. & Ethanol. & Methanol. \\
\hline Staphylococcus aureus & 25 & No & 25 \\
Pseudomonas aeruginosa & 25 & 25 & 25 \\
Escherichia coli & 25 & No & No \\
Aspergillus niger & 25 & 12.50 & 25 \\
Aspergillus fumigatus & 25 & 25 & 25 \\
Candida albicans & No & 25 & 25 \\
\hline
\end{tabular}

Key: $\mathrm{No}=$ value for $\mathrm{MBC}$ was obtained.

Table 15. MBC values of Acetone, Ethanol and Methanol Extracts of Neem Stem Bark.

\begin{tabular}{llll}
\hline \multirow{2}{*}{ Type of Microbe. } & \multicolumn{4}{l}{ Neem Leaf Extract. } \\
\cline { 2 - 4 } & Acetone. & Ethanol. & Methanol. \\
\hline Staphylococcus aureus & No & 25 & 12.50 \\
Pseudomonas aeruginosa & 12.50 & 25 & 25 \\
Escherichia coli & 25 & No & 12.50 \\
Aspergillus niger & 25 & 25 & 25 \\
Aspergillus fumigatus & 25 & 25 & 25 \\
Candida albicans & No & No & No \\
\hline
\end{tabular}

Key: $\mathrm{No}=$ value for MBC was obtained. 


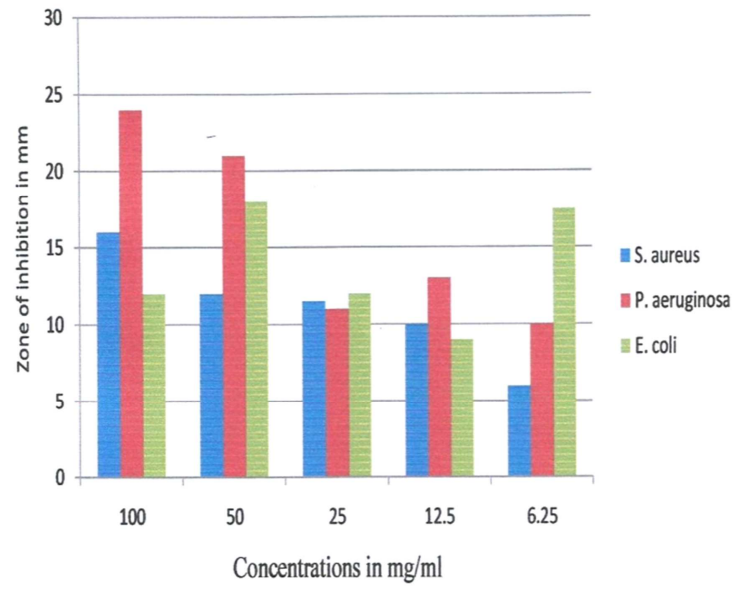

Figure 1. Showing the Antibacterial Activity of Stem Bark Acetone Extract of Neem Plant.

From the graph above, the most susceptible was $P$. aeruginosa, followed by E. coli and Staphylococcus aureus was the least susceptible to the acetone extract of the stem bark extract.

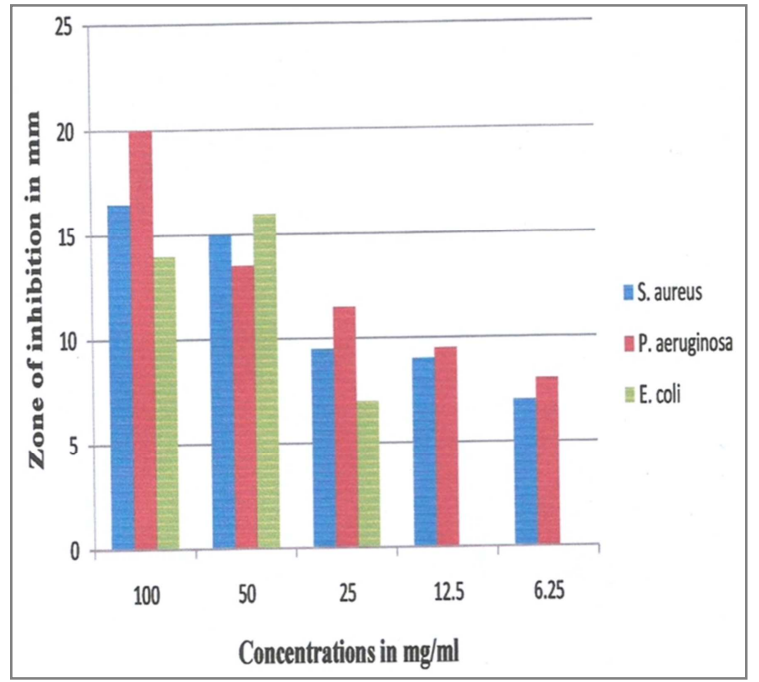

Figure 2. Showing the Antibacterial Activities of Ethanol Leaf Extract of Neem.

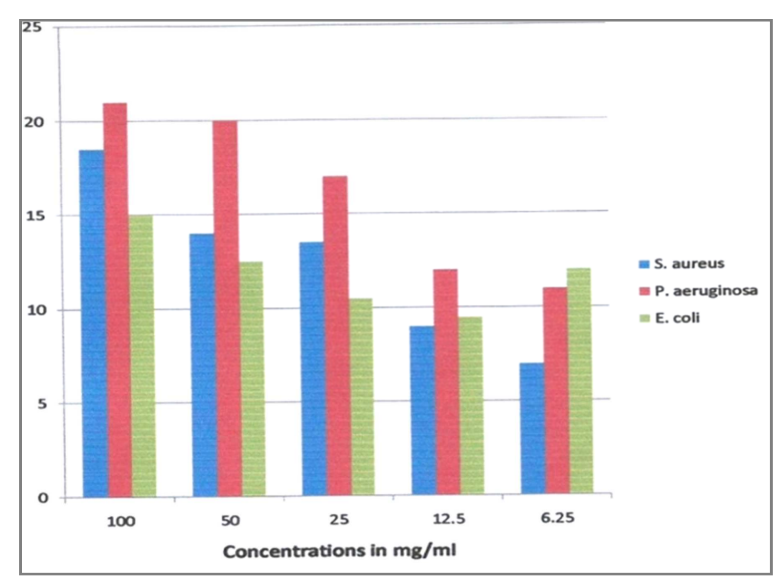

Figure 3. showing the Antibacterial Activities of Ethanol Stem Bark Extract of Neem.
The ethanol extract of stem bark from fig. 3 had more activity than that of the leaf extract showed in fig. 2 above. The ethanol leaf extract had no activity against $E$. coli at 12.5 $\mathrm{mg} / \mathrm{ml}$ and $6.25 \mathrm{mg} / \mathrm{ml}$ but that of the stem bark extract had activity against $E$. coli at these concentrations.

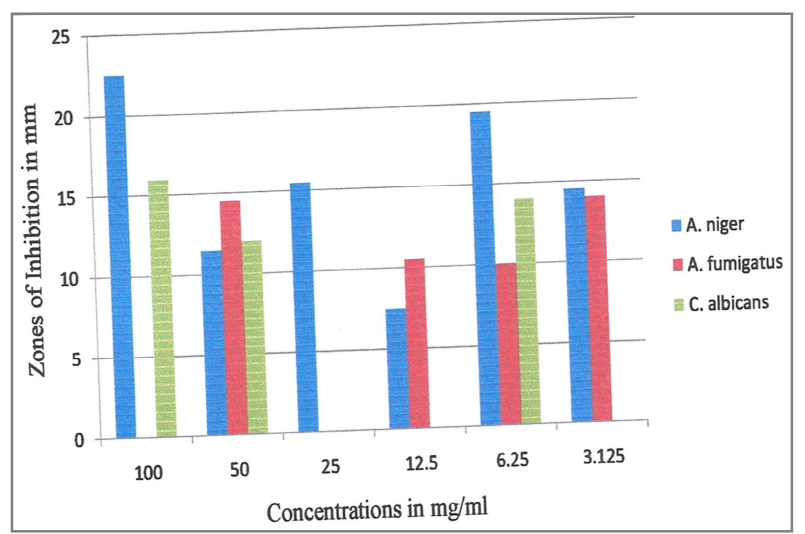

Figure 4. Showing Antifungal Activities of Stem Bark Methanol Extract of Neem.

From the figure above, A. niger was the most susceptible against the methanol extract of stem bark followed by $A$. fumigatus while $C$. albicans showed the least activity. $C$. albicans was resistance against this extract at $25 \mathrm{~g} / \mathrm{ml}, 12.5$ $\mathrm{mg} / \mathrm{ml}, 3.13 \mathrm{mg} / \mathrm{ml}$ and $1.56 \mathrm{mg} / \mathrm{ml}$.

\section{Discussion}

Plant metabolites (phytochemical), with unknown pharmacological activities have been extensively investigated as a source of medicinal agents. The findings of the preliminary phytochemicals investigations and the results of antimicrobial activity were depicted in the respective tables and figures. The results of phytochemicals in the present investigation showed that the Neem plant leaf contain eight phytochemicals components which agree with the works of some researchers as Mohapatra et al., 2014; Abdullah et al., 2011; Chattopadhyay, 1993; such as alkaloids, tannin, glycoside, anthraquinones, reducing sugar, polyphenol, terpenoid and steroid. The presence of these phytochemicals constituents are the reasons leaf and bark acetone, ethanol and methanol extracts have antimicrobial activity.

The difference in the antimicrobial efficacy could be due to variable distribution of phytochemicals compounds in different parts, also the Neem plant stem bark extracts contain the following components like alkaloids, tannin, reducing sugar, polyphenol, and flavonoids. From the results of the phytochemical analysis, it was observed that the stem bark methanol extract contains alkaloid which is absent in the leaf extract. The reducing sugar content is strongly present in the leaf extract while it is present in the bark. Polyphenol is present in the bark's methanolic extract but it is absent in the leaf methanolic extract. The leaf methanolic extract contains tannin but this is absent in the bark extract. Both methanolic extract of leaf and bark do not contain anthraquinones, terpenoid, steroids, glycosides and flavonoid, this in line with 
the work of Asif (2012).

The extracts that showed high antibacterial activity is acetonic stem bark extract against Pseudomonas aeruginosa $(22 \mathrm{~mm})$ followed closely by ethanolic stem bark extract against the same organism $(21 \mathrm{~mm})$. For the leaf extracts, the ethanolic leaf extract had the highest antibacterial activity against Pseudomonas aeruginosa $(20 \mathrm{~mm})$, while the least antibacterial activity was against Escherichia coli in acetonic and ethanolic extracts. More so ever, it was observed that the methanolic stem bark extract of Neem plant had the highest antifungal activity against Aspergillus niger $(22.50 \mathrm{~mm})$. This is followed by ethanolic stem bark extract against Aspergillus fumigatus. Stem bark extracts had low antifungal activity especially against Candida albicans, with these results obtained; it revealed that the studied plant parts (stem bark and leaves) contains both antifungal and antibacterial agents and which in conformity with the works of Asif (2012) and Jayasree et al., (2014).

Overall, the extract of the neem plant part with no antimicrobial activity was that of the stem bark methanolic extract against $C$. albicans. In addition, stem bark extracts, with maximum zone of inhibition as $22.50 \mathrm{~mm}$, had significant antimicrobial activity than the leaf extracts. The highest and lowest zones of inhibitions were $22.5 \mathrm{~mm}$ and 6 $\mathrm{mm}$ respectively. From the experiment done, about one quarter of the results showed that as the concentrations of the plant extracts increases, the zone of inhibitions also increases. But majority of the results obtained do not agree with this relationship. This means that in some situations as the concentrations of the extracts increase, there is a decrease and later a sharp increase in the zones of inhibition.

From the results of the colonial characteristics, the morphological characteristics and the biochemical characteristics of the isolates used for this experiment showed that they were Escherichia coli, Pseudomonas aeruginosa and Staphylococcus aureus. Also, the morphological characteristics and the slide culture results showed that the moulds used were that of Aspergillus niger and Aspergillus fumigatus. The germ tube test showed that the isolate was $C$. albicans as were described by Joanne et al., (2011).

From the results obtained, it revealed that, the most susceptible bacterium was $P$. aeruginosa, followed by $E$. coli and Staphylococcus aureus was the least susceptible to the acetone extract of the stem bar extract. The ethanol extract of stem bark from fig. 3 had more activity than that of the leaf extract showed in fig. 2 above. The ethanol leaf extract had no activity against $E$. coli at $12.5 \mathrm{mg} / \mathrm{ml}$ and $6.25 \mathrm{mg} / \mathrm{ml}$ but that of the stem bark extract had activity against $E$. coli at these concentrations. A. niger was the most susceptible against the methanol extract of stem bark followed by A. fumigatus while C. albicans showed the least activity. C. albicans was resistance against this extract at $25 \mathrm{~g} / \mathrm{ml}, 12.5 \mathrm{mg} / \mathrm{ml}, 3.13$ and $1.56 \mathrm{mg} / \mathrm{ml}$. That means, the acetonic stem bark extract contains more antimicrobial agent than the leaves extract which in conformity with the work of Asif (2012).

All test strains of fungi were found to be sensitive to the standard drugs (antimicrobial agents) used in this work;
Fluconazole and bacteria strain were also sensitive to ciprofloxacin. Results of the agar well diffusion method are shown above, that the leaf extract exhibited antimicrobial activity against all the tested organisms at all concentrations. The bark acetonic extract exhibited significant antimicrobial activity on Pseudomonas aeruginosa, E. coil, Staphylococcus aureus and Aspergillus fumigatus. The bark ethanolic extract exhibited significant antimicrobial activity on $P$. aeruginosa, Staphylococcus aureus and its fungi activity was highest at high concentration against Aspergillus fumigatus. The bark methanolic extract exhibited significant antimicrobial activity on Aspergillus niger, Candida albicans and unusually significant activity against $A$. fumigatus at low concentration its bacterial activity was highest at high concentration on Staphylococcus aureus, P. aeruginosa and E. coli. The leaf acetonic extract exhibited significant antifungal activity on $A$. fumigatus and C. albicans at lower concentrations. The leaf ethanolic extract exhibited significant antimicrobial activity on $P$. aeruginosa, S. aureus and E. coli and it fungi activity was highest on $A$. fumigatus followed by $C$. albicans. The leaf methanolic extract exhibited significant antimicrobial activity on $P$. aeruginosa, $S$. aureus and its fungi activity was highest on A. fumigatus. This showed and proved that the plant parts of $A$. indica contains some antimicrobials agents responsible these activities.

Minimum inhibitory concentration (MIC) values of the $A$. indica acetonic, methanolic and ethanol extracts of leaf and bark and Minimum inhibitory concentration was tested for the acetonic, ethanol and methanol extracts of leaves and bark were ascertained. The results of this study revealed that MIC for leaf acetonic extract was $25 \mathrm{mg} / \mathrm{ml}$ for all organisms except C. albicans which was $12.5 \mathrm{mg} / \mathrm{ml}$. MIC values for the ethanol extract of leaf and bark for fungi were $12.5 \mathrm{mg} / \mathrm{ml}$ and $6.25 \mathrm{mg} / \mathrm{ml}$ respectively. No MIC values were obtained for acetone bark extract for Staphylococcus aureus and ethanol extract also for $S$. aureus.

The same result was obtained for the E. coli in ethanol and methanol leaf extracts. Minimum bactericidal concentration (MBC) values of the Neem acetone, ethanol and methanol extracts of leaf and bark were also obtained. Minimum bactericidal concentration was tested for the acetone, ethanol and methanol extracts of leaves and bark. Results revealed that the MBC for leaf acetone extract was $25 \mathrm{mg} / \mathrm{ml}$ except for $C$. albicans whose MBC was not obtained. The MBC value for the methanol extract of leaf was $25 \mathrm{mg} / \mathrm{ml}$ for all organisms except for $E$. coli whose MBC value was not obtained. No MBC values were obtained for ethanol and methanol leaf extracts and ethanol extract of bark for E. coli. Also, no MBC values were obtained for acetone extract of leaf and acetone, ethanol and methanol extracts of bark for C. albicans. The standard antibacterial drug used as control (ciprofloxacin) indicated that $E$. coli was the most susceptible to the drug followed by Staphylococcus aureus and Pseudomonas aeruginosa. These present study revealed that, there are some phytochemicals with the potency and efficacy for antimicrobial activities and support the works of most researchers on the medicinal plants, especially the Neem plant in concerned. 


\section{Conclusion}

This investigation was done to find out the antimicrobial activity of leaf and bark extracts of Neem plants against selected pathogens. From the above study, A. indica which is used in folkloric traditional medicine showed that it is active against bacterial and fungal strains but there were some degree of variation in their antimicrobial activities. Thus, it may be concluded that $A$. indica leaf and bark extracts have antimicrobial activity against these pathogens. This plant could be utilized as an alternative source of useful antimicrobial drugs. However, extensive research still needs to be done on phytochemicals of this plant for the development of cost effective drugs for the future. More so, since many of the existing synthetic drugs cause various side effects, drug development using plant based compounds could be useful in meeting this demand for newer drugs with minimal side effects.

\section{Acknowledgement}

We acknowledge with most honoured, duly respected and most grateful to the management of: Glanson Medical centre, Awka; Department of Botany, Department of Applied microbiology and brewing Laboratory, Azikiwe University, Awka for providing the stock culture; Laboratory Unit, AHP Department, Mohamet Lawan College of Agriculture, Maiduguri, SLT Department, Waziri Umaru Federal Polytechnic, Birnin Kebbi, Nigeria, for providing some of the materials, and any other persons, few to mentioned, that helped and aided us in the course of carrying out this research study ssuccessfully.

\section{References}

[1] Abdullah, A., Shahed, S. A., Farzana, A., Sajal, K., Sreedam, C. D., and Sitesh, C.B. Evaluation of brine shrimp lethality and antimicrobial activity of $A$. indica leaf extract on some drugs resistance bacteria in Bangladesh. Pharmacognosy Journal, 20 (3): 66 - 71. 2011.

[2] AOAC, Official Methods of Analysis, In: Association of Official Analytical Chemists, AOAC Press; Gaithersburg, Washington D.C, USA. $15^{\text {th }}$ Edition; Pp. 71-92. 1990.

[3] Asif, M. Antimicrobial Potential of A. indica Against Pathogenic Bacteria and Fungi. Journal of Pharmacognosy and Phytochemistry, 1 (4), Pp: 78 - 83. 2012.

[4] Auwal, M. S.; Gwana, M. A; Isma'ila, A. M; Bagudu, B. Y; Shu'ibu, A. and Hambagda, A. Phytochemicals Properties and In vitro Antibacterial Activity of Aqueous Extract of Jatropha caucus Root Bark. Journal of Laboratory Science, 1 (1); Pp: 1 -6. 2012 .

[5] Ayoola, P. B; Adeyeye, A; Adelowo, F; Onawumi, O. O, Evaluation of the Chemical and Nutritional Values of Some Nigerian water melon (Citrullus lanatus), Journal of Laboratory Science, Volume 1, number 1; Pp: 37 - 41. 2012.

[6] Bandow, J. E; Brotz, H; Leichert, L. I. O; Labischinski, H. and Hecker, M. Proteonic Approach to Understanding Antibiotic
Action. Antimicrobe Agents Chemother, 47 (3); Pp: 948 - 955. 2003.

[7] Biotec. Medical Market U.K Limited, 37 Stanmore Hill, Stanmore, Middlesex, HA 73 DS.

[8] Chattopadhyay, R. R.; Chattopadhyay, R.; N. and Maitra, S., K. Possible Mechanism of anti-inflammatory activity of $A$. indica leaf extracts. Indian Journal of Pharmacology, 25; Pp: $99-100.1993$.

[9] Egan, H.; Kirk, R. S. and Sawyer, R. Pearson's Chemical Analysis of Foods. $8^{\text {th }}$ Edition. Churchill, Livingstone, N. Y; Pp: 27 - 56. 1981.

[10] Fernando, M. R; Wickramasinghe, M. D; Thabrew, M. I; Karnayaka, E. K. A Preliminary Investigation of the Possible Hypoglycemic Activity of Asteracanthus longifolia. $J$. Ethnopharmacol., 27, Pp: 7 - 14. 1989.

[11] Galal, M.; Bashir, A. K ; Salih, A. M. and Adam, S. E. Activity of Water Extracts of Albizia anthelmintica and A. lebbek bark against Experimental Hymenolepsi diminuta Infection in Rats. J. Ethnopharmacol. 31; Pp: 333 - 337. 1991.

[12] Gwana, A. M.; Bako, M.M.; Bagudu, B. Y.; Sadiq, A. B.; Abdullahi, M. Mai. Determinations of Phytochemical, Vitamin, Mineral and Proximate Compositions of Varieties of Water melon Seeds Cultivated in Borno State, North - Eastern Nigeria. International Journal of Nutrition and Food Sciences. Vol. 3, No. 4, 2014, pp. 238 - 245. doi:10.11648/j.ijnfs. 20140304. 12.

[13] Hoffmann, J. J; Timmerman, N; McLaughlin, R.; Punnapayak, H. Potential Antimicrobial Activity of Plants from the South Western United State. Int. J. Pharmacol., 31; Pp: $101-115$. 1993.

[14] Jayasree, T., Anuradha, B. and Praveena. Antimicrobial activity of methanolic extracts of $A$. indica, Rosmarinus officinalis and Leenaria siceraria leaves on some important pathogenic organisms. Journal of Chemical and Pharmaceutical Research, 6 (4); Pp: 766 - 770. 2014.

[15] Joanne, M. Willy, Linda, M. Sherwood and Christopher, J. Woolverton. Cinical Microbiology and Immunology, In: Prescott's Microbiology. $8^{\text {th }}$ Edition, McGraw - Hill Companies, New York, USA; Pp: 850 - 871. 2011.

[16] Lai, P. K. Antimicrobial and Chemopreventive properties of herbs and spices. Current Medicinal Chemistry, P: 1451 1460. 2004.

[17] Lale, N. E. S. Bio - activity and Limitation against wide spread use of Neem products for the management of insect pests. Nigerian Journal of Applied Biology, 3; Pp: 115 - 12. 2002.

[18] Merck, E. Merck D - 61 Darmstadt, Tel. (06151) 720.

[19] Mahapatra, Shames, R. J.; Holmes, M. W.; Young, C. Y.; Cheville, J. C.; Kohli, M. Novel molecular targets of $A$. indica associated with inhibition of tumor growth in prostate cancer. American Association of Pharmaceutical Scienties Journal, 13 (3); Pp: 365 - 377. 2011.

[20] Manikandan, P.; Anandan, R. and Nagini, S. Evaluation of $A$. indica leaf fraction for in vitro antioxidant potential and protective effects against hydrogen peroxide induced oxidative damage top BR 322 DNA and red blood cells. Journal of Agricultural Food Chemistry, 57 (15); Pp: 6990 96. 2009. 
[21] Oyi, A. R; Omaolapo, J. A; Haruna, A. H; Morah, C. O. Antimicrobial Screening and Stability Studies of the Crude Extract of Jatropa caucus Linn Latex (Euphorbiaceae). Nigeria Journal Pharmaceutical Science, 6 (2); Pp: 14 - 20. 2007.

[22] Santos, P. R. V.; Oliveira, A. C. X. ; Tomassini, T. C. B. Contrôle Microbiologicode Produtos Fitoterapicos. Rev. Farm Bioquim, 31; Pp: 35 - 38. 1995.

[23] Sekoni, Tindal, and Adeniran. Medicinal Plant in Africa. Pp: $34-40.1984$.
[24] Srinivasan, D.; Nathan - Sangeetha, T.; Suresh, P.; Lakshamana, P. Antimicrobial Activity of Certain Indian Medicinal Plants Used in Folkric Medicine. $J$. Ethnopharmacol. 74 ; Pp: 217 - 220. 2001.

[25] Stray, F. The Natural Guide to Medicinal Herbs and Plants. Tiger Books International, London, $1^{\text {st }}$ Edition; Pp: $12-16$. 1998. 